\title{
A Framework for the Reliability Analysis of Wind Turbines against Windstorms and Non-Standard Inflow Definitions
}

\author{
Lance Manuel $^{1}$ \\ Dept. of Civil, Architectural, and Environmental Engineering, University of Texas, Austin, TX 78712, USA \\ and \\ Paul S. Veers ${ }^{2}$ \\ Wind Energy Technology Department, Sandia National Laboratories, Albuquerque, NM 87185, USA
}

\begin{abstract}
The development and application of design standards has been a critical element in raising the level of reliability across the entire wind energy industry. Designs have an objective set of criteria against which they can be judged and entire fleets of turbines can be manufactured to a common set of criteria. Each wind power development is then left with the task of assessing whether or not a particular turbine designed for a standards-driven class is appropriate for a particular site. There are increasing numbers of turbines deployed in sites that possess unusual wind speed and turbulence characteristics, perhaps driven by complex terrain or other special features. The effects of atmospheric stability and stratification can also lead to off-design loadings. A unified approach to dealing with the risks using an event tree framework is applied to identify and organize the critical assessments needed to fill out the risk portfolio. This approach is applied to normal operation as well as to the variants or off-standard atmospheric conditions that could be encountered including extreme atmospheric events. Many of the characteristics of extreme atmospheric events that impact typical wind turbine systems are yet to be characterized in ways that drive aeroelastic loads and design criteria. Hurricanes, thunderstorms, and tornadoes have well-studied influences on buildings, bridges, etc., but the coherence structure and turbulence kinetics at the spatial scale of wind turbine rotors are not as well documented. This study examines the aeroelastic response of a wind turbine to example offstandard and extreme atmospheric conditions and maps out site criteria that provide direction in conducting a risk assessment.
\end{abstract}

\section{Introduction}

$\mathrm{T}$ he IEC 61400-1 standard ${ }^{1}$ for wind turbines outlines minimum design requirements for wind turbines. It is not intended for use as a complete design specification as it very clearly states. Indeed, the various design load cases outlined in Section 7 of the standard, "Structural Design," attempt to address eight different critical design situations (including Power production, Normal shut down, etc.) and consider both ultimate and fatigue limit states. Importantly, these load cases also take into consideration numerous important external condition assumptions (defined in Section 6 of the standard) related mainly to atmospheric turbulence. For instance, they address normal turbulence in near-neutral stability of the atmosphere, extreme operating gusts, extreme direction change, extreme wind shear, etc.

Clearly, the standard ${ }^{1}$ has evolved to where numerous possibly critical considerations are accounted for as part of the design process. Despite this, though, for a wind turbine or wind farm, other site-specific or region-specific considerations related to local considerations such as nocturnal low-level jets (LLJs) in stable atmospheres, thunderstorm downbursts, tornadoes, hurricanes, etc. could possibly be important in site assessment and in verification that the design envelope implied by the standard is adequate.

\footnotetext{
${ }^{1}$ Associate Professor

${ }^{2}$ Distinguished Member of the Technical Staff
} 
As defined in the standard ${ }^{1}$, site assessment requires site-specific consideration (beyond the design load cases) of topographical complexity, extreme winds, turbulence intensity, flow inclination, wind shear, air density, wind farm wakes, icing, humidity, lightning, solar radiation, salinity, earthquakes, the electrical network, and soil conditions. In the following, we are concerned mainly with what we will characterize as "hazards," those offstandard atmospheric inflow conditions that could include normal turbulence and other external conditions defined in the standard as well as others not explicitly addressed there. For instance, if a site such as one in Lamar, Colorado is being assessed, the possibility of nocturnal low-level jets and other climatic hazards needs to be accounted for. The influence of these types of inflow conditions at such sites has been studied in field measurement campaigns where both turbulence data and turbine loads data have been recorded (see Fig. 1). Such studies are useful in evaluating the effect of hazards on turbine loads but such tests are extremely expensive to conduct. An alternative approach must rely on simulation both of the appropriate inflow conditions associated with a given hazard as well as of the aeroelastic response of the turbine to such flows. For Great Plains sites, for instance, there has been considerable interest in evaluating the influence of nocturnal low-level jets on turbine loads and fatigue. Several recent studies have focused on this phenomenon ${ }^{2-5}$ and associated deviations (from the standard) in wind speed shear as well as direction shear that accompany these flows that are manifested in stable boundary layers. These wind field characteristics are outside the envelope of external conditions in the standard ${ }^{1}$ which only considers neutral atmospheric conditions. From the point of view of modeling based on simulation, tools such as TurbSim ${ }^{6}$ developed $^{2}$ at the National Renewable Energy Laboratory have even made it possible to simulate turbulence random fields that include low-level jet events. More realistic procedures for stable boundary layer (SBL) flow generation such as large-eddy simulation (LES) are also available, even if somewhat more expensive computationally. ${ }^{7}$ LES-generated flows can describe LLJs and wind shears that may be of interest in the design process. With such simulated turbulence fields, it is possible to evaluate what effect spatially organized coherent structures with scales on the order of a turbine rotor radius can have on turbine loads. Today's utility-scale turbines have hub heights and rotor diameters that are well within the range of interesting low-level jet events and their consideration in site assessment can be evaluated in the event tree framework we are seeking to develop.
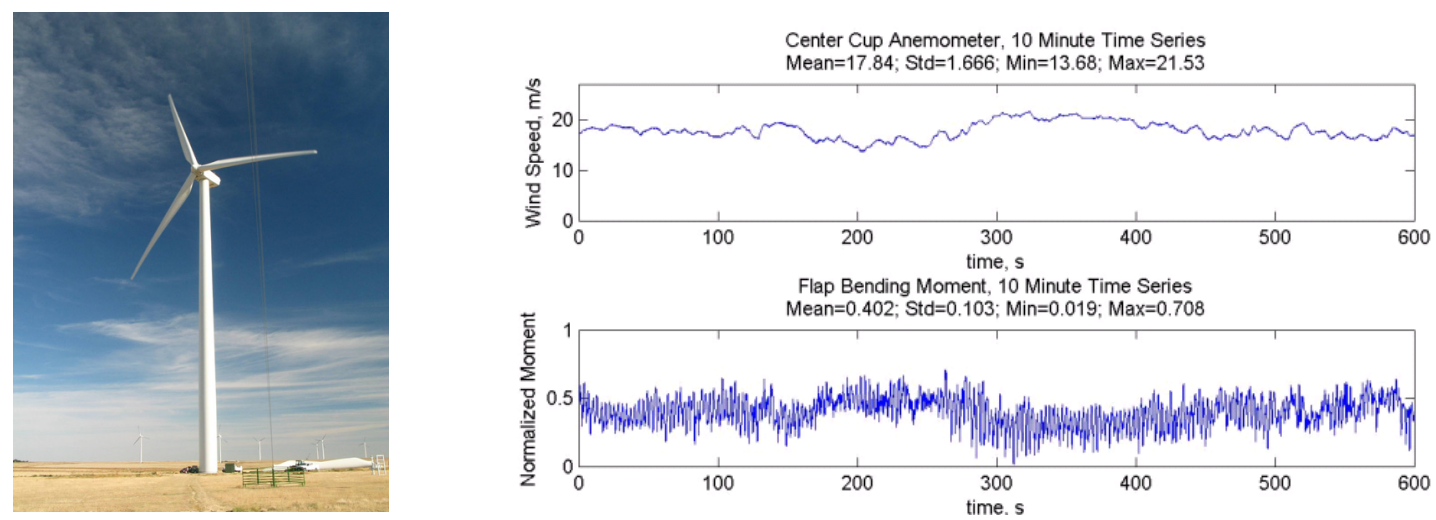

Figure 1. (a) Instrumented utility-scale 1.5MW wind turbine in Lamar, Colorado; (b) site-specific hub-height turbulence and measured blade loads.

In addition to LLJs, windstorm hazards such as thunderstorm downbursts, tornadoes, hurricanes, etc. are also of interest. Description of flows generated by such hazards is challenging but, with proper parameterization, it is possible to include these windstorm hazards as well in a reliability framework as we shall see in separate illustrative examples involving LLJs and thunderstorm microbursts.

\section{An Event Tree Approach for Addressing Hazards}

The overall risk to a wind turbine or a wind farm may be evaluated in a manner similar to how the IEC 61400-1 standard ${ }^{1}$ currently deals with Design Load Case 1.1 which addresses an ultimate limit state for "Normal Turbulence Model" (NTM) inflow turbulence over a turbine's operating range. There, one is required to establish a 50-year 
"characteristic" load that is then used in a design checking equation. For all wind speeds between cut-in and cut-out, NTM-based simulations of the turbulence are followed by aeroelastic simulations of turbine loads until the desired load level, $l$, is derived for the target probability, $p_{T}$, associated with a 50 -year return period. This can be given by Eq. (1).

$$
p_{T}=P[L>l]=\sum_{\text {all }} P\left[L>l \mid V_{N T M}\right] P\left[V_{N T M}\right]
$$

where $V_{N T M}$ refers to the hub-height 10-minute mean wind speed and $L$ refers to the load measure of interest (usually, a time basis of 10 minutes is used and the probability, $p_{T}$, associated with the 50 -year return period is converted to an associated target probability of load exceedance in 10 minutes).

In the context of other hazards outside of the standard, i.e., beyond neutral atmospheric conditions and the NTM, it is possible to use a similar approach as suggested by Eq. (2).

$$
\frac{1}{T}\left(\mathrm{yr}^{-1}\right)=\sum_{\text {all hazards }} P\left[L>l \mid \text { Hazard }_{i}\right] \cdot v\left[\operatorname{Hazard}_{i}\right]
$$

where each possible hazard is explicitly considered when seeking to meet the target performance goal, which is still a probabilistic design criterion such as the search for the $T$-year load. The most important difference now is that the target probability of exceedance is stated as a target rate of exceedance equal to $1 / T$ (per year). Also, the annual rate of occurrence of the specific hazard in question is given as $v\left[\operatorname{Hazard}_{i}\right]$ while $\mathrm{P}\left[L>l \mid \mathrm{Hazard}_{i}\right]$ represents the probability of exceedance of load, $l$, given that the hazard occurs. If only a single hazard is of concern, whose rate of occurrence per year is $v$, then the desired $T$-year load, $l$, must have a probability of exceedance (given the hazard) that is equal to $1 / v T$.

In attempting to address Eq. (2), complications arise due to the need to able to (a) establish meteorologically the rate of occurrence of each hazard which requires climatological historic data pertinent to the hazard; and (b) to simulate loads conditional on the selected hazard and its associated inflow conditions. Indeed, the latter problem is especially challenging and, depending on the specific hazard, might require consideration of such complexities as the use of stationary versus non-stationary spectral representations of turbulence, coherent structures, transient versus steady-state atmospheric conditions, turbulence bursts, coherence structures, rotation/vorticity versus straight line winds, etc. Here, we introduce a reliability/risk framework that considers multiple hazards. Necessarily, each hazard will need to be parameterized by a set of essential physical quantities that will be needed to inform the process of simulating realistic flow conditions that a turbine may experience and for which loads will be estimated. For demonstration purposes, we will use two different hazards in this study-a low-level jet which can be thought is as an off-standard "hazard" in that it is not directly addressed in today's turbine design guidelines and a thunderstorm microburst representing a windstorm hazard, which while not uncommon in many locations, brings about special flow conditions that are again not directly addressed in design load cases in today's standards.

Figure 2 shows schematically a proposed generalized event tree framework that may be used to address different hazards relevant to a turbine site in question. The event tree is developed in a top-down fashion so that as much detail is provided at the bottom-most branches to make it possible to carry out the appropriate type and number of flow simulations so that the conditional probability, $\mathrm{P}\left[L>l \mid \operatorname{Hazard}_{i}\right]$ in Eq. (2) may be estimated. The details required might include characteristics - physical, statistical, etc. - of the wind shear, turbulence spectral models, etc.

The conditional load distribution given the hazard in question that appears in Eq. (2) must be further characterized in terms of a vector of parameters, $\Theta_{i}$, specific to hazard $i$. The choice of parameters to include in $\Theta_{i}$ will depend on the specific hazard in question. These parameters must be sufficient to describe the essential characteristics of the inflow wind velocity field during the occurrence of the hazard; additionally, uncertainty in these parameters must be described as completely as is possible given observational data and physical models. We consider two examples next. 


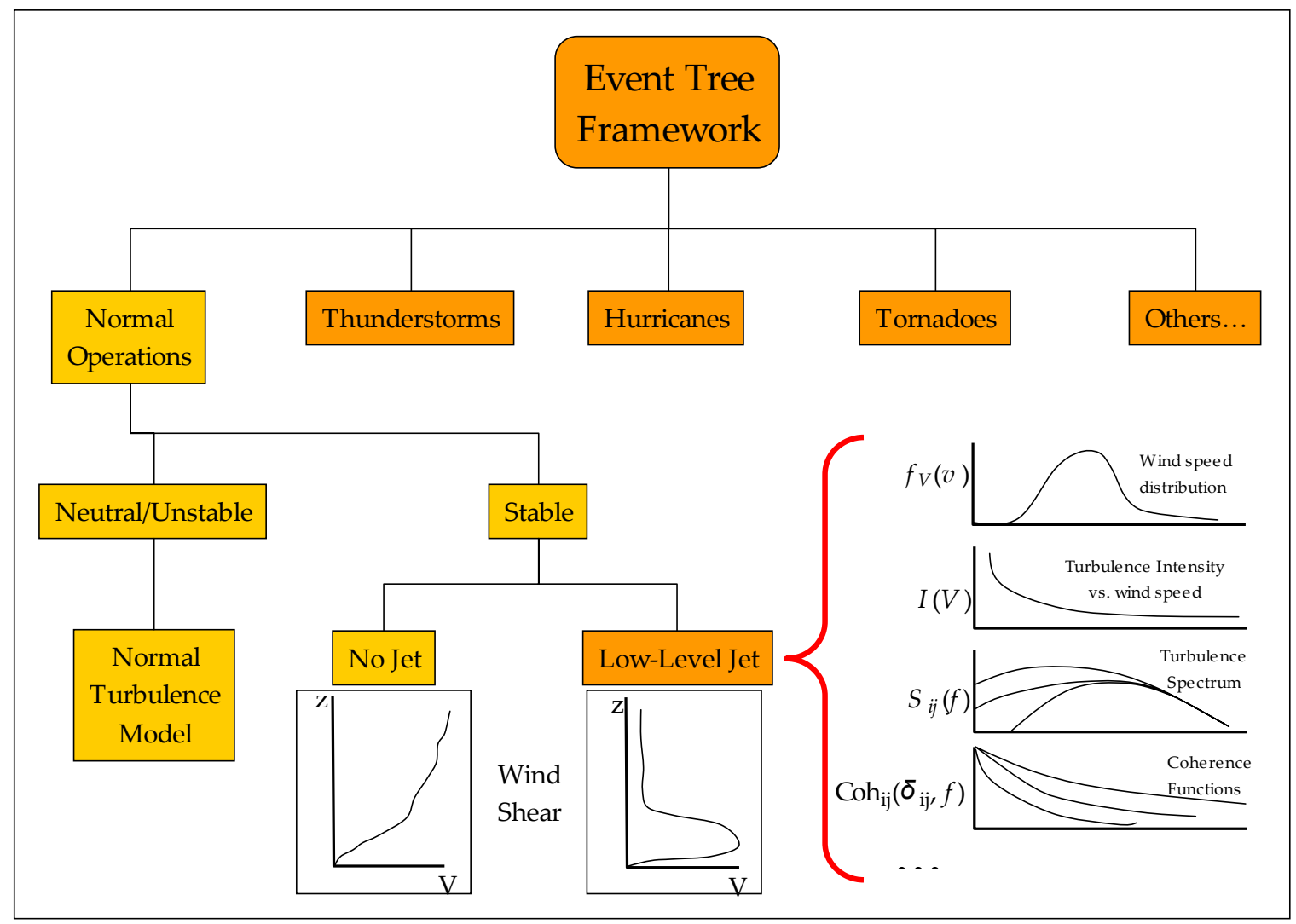

Figure 2. Event tree framework for addressing windstorms and off-standard hazards.

\section{An Off-standard "Hazard": Low-Level Jet}

Stable boundary layer (SBL) flows are often accompanied by low-level jets (LLJs); wind shear then is different from what is assumed in neutral conditions. Wind turbine design standards do not address LLJs, which can These LLJs can occur at low enough elevations to impact today's large utility-scale turbines. Without attempting to fully address all of the details involved in the probabilistic formulation required for Eq. (2), two bulk characteristics of the atmospheric boundary layer that can describe SBL flows and LLJs include the surface temperature cooling rate and the geostrophic wind. These two parameters can be then taken to describe the hazard. Inflow turbulence and loads are simulated on the rotor and the tower of a 90-meter hub-height 5MW wind turbine. Large-Eddy Simulation (LES) was used to generate flows and the simulated wind velocity fields were then fed into an aeroelastic model of the selected wind turbine. Figure 3 shows a 15-minute slice of longitudinal wind velocity field over a 180-meter vertical section; for the case shown (where the cooling rate was $0.25 \mathrm{~K} / \mathrm{hr}$ and the geostrophic wind speed was 15 $\mathrm{m} / \mathrm{s}$ ), the LLJ formed at $430 \mathrm{~m}$. Various other cases (for different cooling rates and geostrophic winds) have also been studied and are reported elsewhere ${ }^{8}$; LLJs were seen to occur at heights ranging from 130 to 630 meters. In addition significant wind speed and direction shear were observed - power law exponents were as large as 0.37 and direction change were as large as 30 degrees from the bottom-most point to the top-most point swept by the rotor (representing elevations ranging from 27 meters to 153 meters).

Turbine loads were simulated using FAST $^{9}$ for the SBL flows with LLJs and these were compared with those for neutral boundary layer flows (that were generated using TurbSim ${ }^{6}$ based on the IEC standard and NTM assumptions). Figure 4 shows how fatigue loads differed in one of the cases studied (the LLJ was at 430 meters for this case where the surface temperature cooling rate was $0.25 \mathrm{~K} / \mathrm{hr}$ and the geostrophic wind speed was $15 \mathrm{~m} / \mathrm{s}$ ).

From the preceding discussions, it is clear that using $\operatorname{LES}^{7}$ and suitable parameterization of important physical variables, contrasting SBL flows with LLJs can be simulated. The only remaining issue is to assess (i) the rate of occurrence of LLJs for a turbine site in question and (ii) the likelihood of various combinations of different 
parameters that describe the flow and the low-level jet. This will require observational data; if the possibility of large loads is high, having such data will be vital for use with the proposed event tree framework.

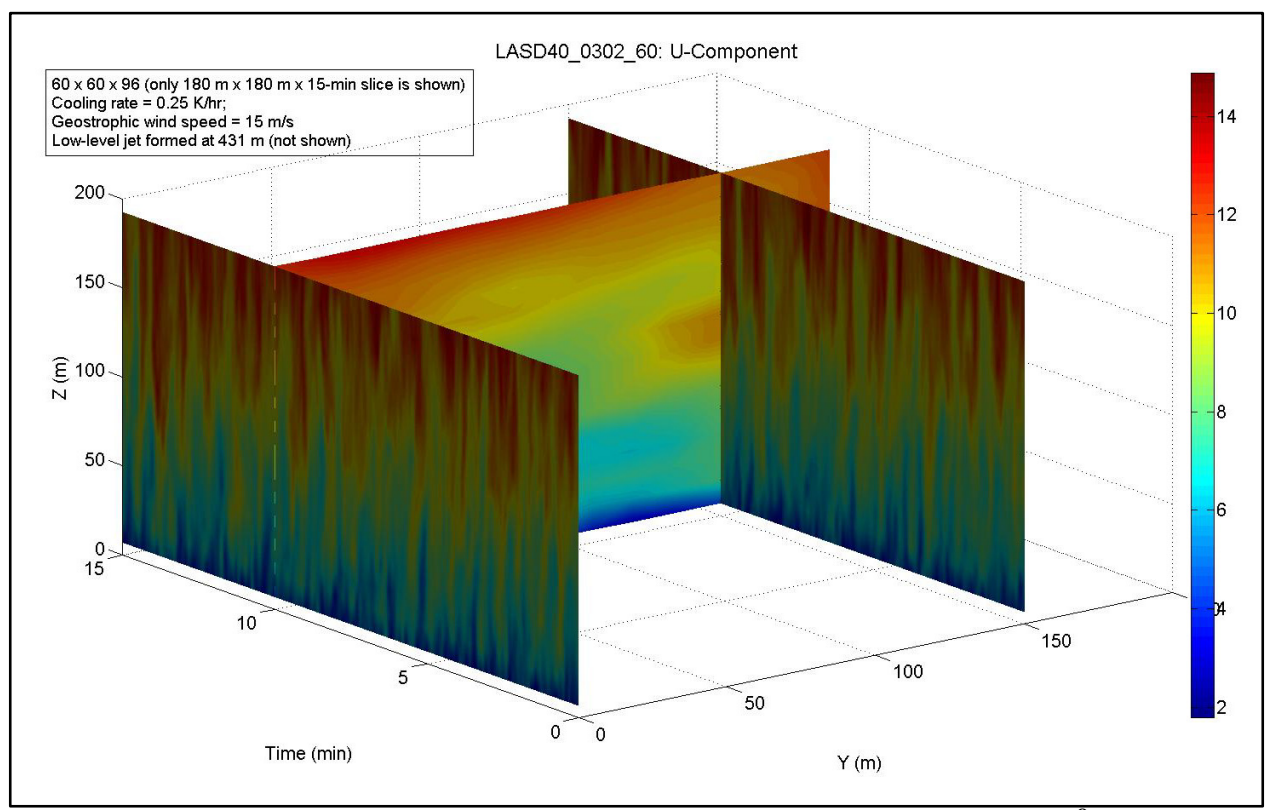

Figure 3. A 15-minute of the longitudinal velocity wind field generated from LES. ${ }^{8}$ A 180-meter vertical section if shown; for the case shown (cooling rate $=0.25 \mathrm{~K} / \mathrm{hr}$ and geostrophic wind speed $=15 \mathrm{~m} / \mathrm{s}$ ), the LLJ formed at $431 \mathrm{~m}$.

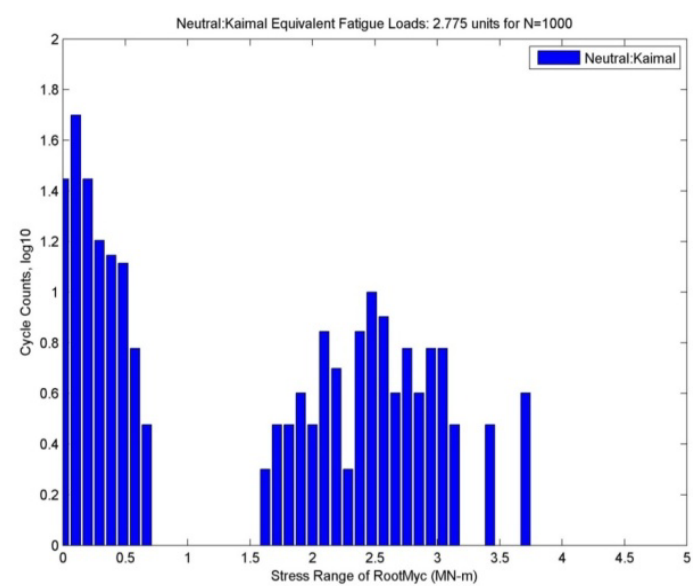

(a)

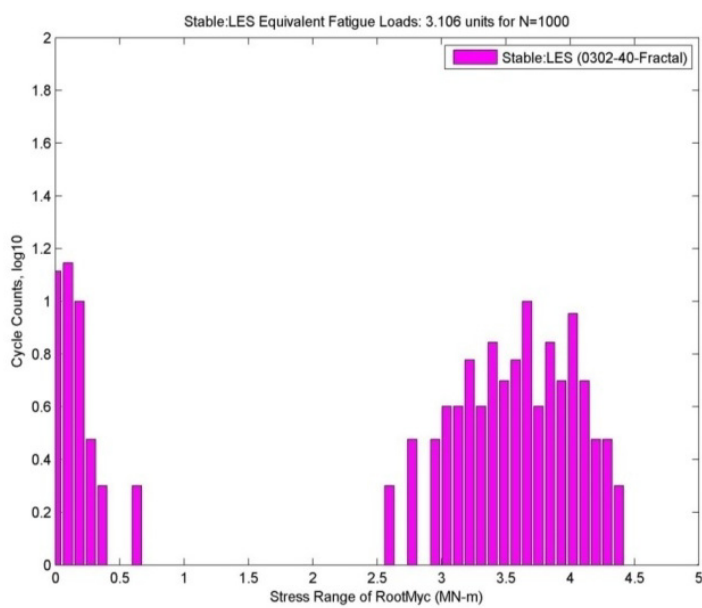

(b)

Figure 4. Fatigue damage histograms and equivalent fatigue loads for (a) neutral and (b) stable boundary layer flows.

\section{A Windstorm "Hazard": Thunderstorm Microburst}

A thunderstorm downburst is a strong downdraft which includes an outflow of potentially damaging winds on or near the ground. ${ }^{10}$ A microburst is a downburst that possesses a diameter smaller than $4 \mathrm{~km}$ and that lasts for less than 5 minutes. A microburst can cause damaging winds as high as $270 \mathrm{~km} / \mathrm{hr}$. There are four stages of thunderstorm outflow, commencing as the parent downdraft descends beneath the base of the clouds. ${ }^{11}$ These include a formative stage, an early mature stage, a late mature stage, and a dissipating stage. 
Models for the non-turbulent winds with a moving front have been developed ${ }^{12-15}$ in the literature for simulating microburst flows. These models may be used to describe horizontal and vertical wind velocity components at any specified location. Physical parameters of most importance in describing the non-turbulent velocity fields include the radius of the downdraft, the storm's translational velocity, the maximum radial velocity, the elevation at which the maximum radial velocity occurs, the time at which the storm reaches its maximum intensity, etc. In addition to the non-turbulence component, wind velocity in a downburst includes a turbulent fluctuation that can be simulated using an auto-regressive moving average (ARMA) process. ${ }^{8}$

For the purposes of illustration, for a site where it is assumed that 30 thunderstorm microbursts occur each year, Monte Carlo simulations were carried out assuming: (1) the radius of downdraft can vary between $500 \mathrm{~m}$ and $5 \mathrm{~km}$; (2) the elevation at which the maximum radial velocity occurs can vary between 50 and $120 \mathrm{~m}$; (3) the storm front's translation velocity can vary between 0 and $15 \mathrm{~m} / \mathrm{s}$; (4) the maximum radial velocity can vary between 20 and 80 $\mathrm{m} / \mathrm{s}$; (5) the radius at which the maximum radial velocity occurs can vary between 1.0 and 1.3 times the radius of the downdraft; and (6) the storm duration can vary from 120 to 300 seconds.
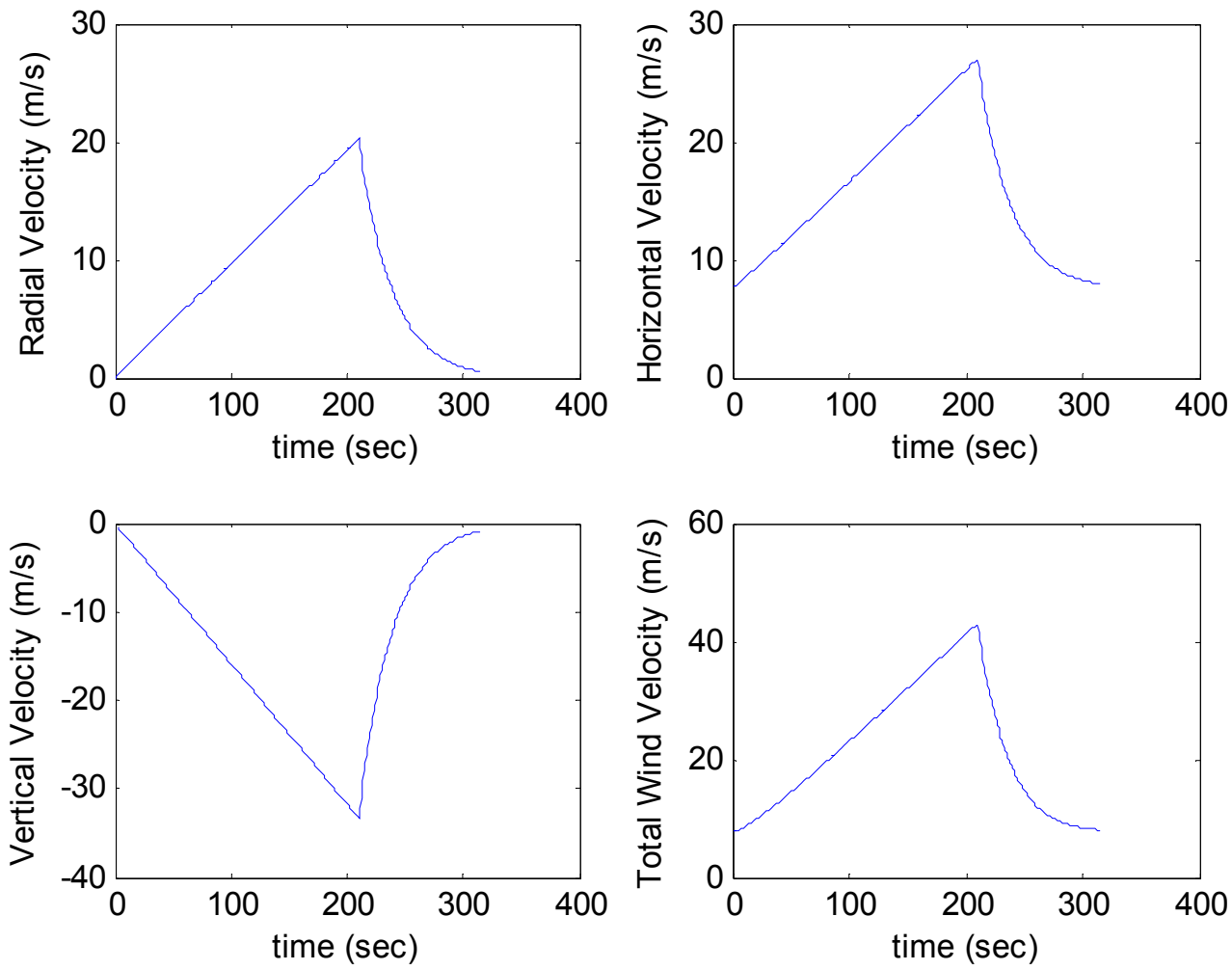

Figure 5. Wind velocity versus time traces (for a microburst lasting 3.5 minutes).

Assuming a turbine with hub height at 90 meters and located $1 \mathrm{~km}$ from the center of a microburst and at an angle 60 degrees east of the storm front's path, the non-turbulent velocity field, on average, Fig. 5 shows wind velocity versus time plots for a microburst lasting 210 seconds. As is clear from the figure, the microburst can cause large horizontal velocities that last for a few seconds; more importantly, vertical (downward) velocities can also be large. The total velocity in the figure represents the resultant of horizontal and vertical velocity components. Based on the Monte Carlo simulations of the parameters that describe the microburst hazard here, it is rather straightforward to develop probabilistic distributions of non-turbulent wind velocity fields that may be applied over the rotor plane of the selected wind turbine. In addition, the ARMA model can be employed to include a turbulent wind velocity component. As with the low-level jet event discussed, turbine loads may then be simulated and 
probabilistic distributions of turbine loads given the microburst and associated statistical variation of the relevant parameters that describe it.

\section{Conclusions}

Design criteria are often set using standards intended to describe typical resource areas. When assessing the suitability for a site, atmospheric conditions at that site are compared to the "standard" site by assessing the sitespecific aeroelastic response of the turbine. Extreme events or hazard also need to be examined. An event tree framework has been presented that can assist in laying out the entire suite of local contributors to the risk of a particular wind power deployment. The atmospheric conditions for two example "hazards"- a low-level jet in stable atmospheric boundary layer conditions and a thunderstorm microburst - are incorporated in this event treebased risk assessment framework; generalization to other hazards can follow a similar path.

\section{Acknowledgements}

The authors are pleased to acknowledge financial support received from Sandia National Laboratories (by way of Contract No: 743358) and from the Texas Higher Education Coordinating Board's Advanced Research Program (Grant No. 003658-0100-2007). They also wish to acknowledge assistance received from Dr. Sukanta Basu (of Texas Tech University) for the low-level jet example and from Mr. Hieu Huy Nguyen (graduate student at the University of Texas at Austin) for the thunderstorm microburst work.

\section{References}

${ }^{1}$ International Electrotechnical Commission, "IEC 61400-1: Wind turbines - Part 1: Design Requirements, Ed. 3, 2005.

${ }^{2}$ Pichugina, Y.L., Banta, R.M., Kelley, N.D., Sandberg, S.P., Machol, J.L., and Brewer, W.A., "Nocturnal Low-Level Jet Characteristics over Southern Colorado," Preprints, 16th Symposium on Boundary Layers and Turbulence, Portland, ME, American Meteorological Society, CD-ROM, 4.11, 2004.

${ }^{3}$ Banta, R. M., Kelley, N. D., and Pichugina, Y. L, "Low-Level Jet Properties and Turbulence below the Jet during the Lamar Low-Level Jet Project," Preprints, 16th Symposium on Boundary Layers and Turbulence, Portland, ME, American Meteorological Society, CD-ROM, 4.10, 2004.

${ }^{4}$ Banta, R.M., Pichugina, Y.L., and Brewer, W.A., "Turbulent Velocity-Variance Profiles in the Stable Boundary Layer Generated by a Nocturnal Low-Level Jet," Journal of the Atmospheric Sciences, 63, 2700-2719, 2006.

${ }^{5}$ Kelley, N. D., Jonkman, B. J., and Scott, N. J., "The Great Plains Turbulence Environment: Its Origins, Impact and Simulation," Conference Paper NREL/CP-500-40176, December 2006.

${ }^{6}$ Jonkman, B. J., and Buhl, Jr., M. L. "TurbSim User's Guide for Version 1.30," National Renewable Energy Laboratory, 2008 .

${ }^{7}$ Basu, S., Porté-Agel, F., "Large-eddy simulation of stably stratified atmospheric boundary layer turbulence: a scaledependent dynamic modeling approach,” Journal of the Atmospheric Sciences, Vol. 63, 2074-2091, 2006.

${ }^{8} \mathrm{Sim}$, C., Basu, S., and Manuel, L., "The influence of stable boundary layer flows on wind turbine fatigue loads," Proceedings of the 47th AIAA Aerospace Sciences Meeting Including The New Horizons Forum and Aerospace Exposition, Orlando, Florida, 2009.

${ }^{9}$ Jonkman, J. M. and Buhl, M. L. Jr., “FAST User's Guide,” National Renewable Energy Laboratory, NREL/EL-500-38230, Golden, CO, 2005.

${ }^{10}$ Fujita, T. T., "Downburst: Microburst and Macroburst,” Univ. of Chicago Press, Chicago, Illinois, 122 pp., 1985.

${ }^{11}$ Wakimoto, R.M., "The Life Cycle of Thunderstorm Gust Fronts as Viewed with Doppler Radar and Rawinsonde Data," Monthly Weather Review, Volume 110, pp. 1060-1082, 1982.

${ }^{12}$ Oseguera, R. M. and Bowles, R. L., "A simple, analytics 3-dimensional downburst model based on boundary layer stagnation flow," NASATM- 100632. Hampton (VA): NASA Langley Research Center; 1988

${ }^{13}$ Vicroy, D. D., "A simple, analytical, axisymmetric microburst model for downdraft estimation," NASA-TM-104053. Hampton (VA, USA): NASA; 1991.

${ }^{14}$ Vicroy, D. D., "Assessment of microburst models for downdraft estimation,” Journal of Aircraft, 29(6):1043-8, 1992.

${ }^{15}$ Chay, M. T., Albermani, F., and Wilson, R., "Numerical and analytical simulation of downburst wind loads," Engrg. Struct., 28, 240-254, 2006. 